\title{
Global Tactical Cross-Asset Allocation: Applying Value and Momentum Across Asset Classes
}

\author{
David Blitz and Pim van Vliet
}

\begin{tabular}{|l|l|}
\hline \multicolumn{2}{|l|}{ ERIM REPORT SERIES RESEARCHINMANEMENT } \\
\hline ERIM Report Series reference number & ERS-2008-033-F\&A \\
\hline Publication & June 2008 \\
\hline Number of pages & 31 \\
\hline Persistent paper URL & http://hdl.handle.net/1765/12598 \\
\hline Email address corresponding author & pim.van.vliet@robeco.nl \\
\hline Address & Erasmus Research Institute of Management (ERIM) \\
& RSM Erasmus University / Erasmus School of Economics \\
& Erasmus Universiteit Rotterdam \\
& P.O.Box 1738 \\
& 3000 DR Rotterdam, The Netherlands \\
& Phone: +31 10 408 1182 \\
& Fax: $\quad+31104089640$ \\
& Email: info@erim.eur.nl \\
& Internet: $\quad$ www.erim.eur.nl \\
\hline
\end{tabular}

Bibliographic data and classifications of all the ERIM reports are also available on the ERIM website: www.erim.eur.nl 


\section{ERASMUS RESEARCH INSTITUTE OF MANAGEMENT}

\section{REPORT SERIES}

\section{RESEARCH IN MANAGEMENT}

\begin{tabular}{|l|l|}
\hline ABSTRACT AND KEYWORDS \\
\hline Abstract & $\begin{array}{l}\text { In this paper we examine global tactical asset allocation (GTAA) strategies across a broad range } \\
\text { of asset classes. Contrary to market timing for single asset classes and tactical allocation across } \\
\text { similar assets, this topic has received little attention in the existing literature. Our main finding is } \\
\text { that momentum and value strategies applied to GTAA across twelve asset classes deliver } \\
\text { statistically and economically significant abnormal returns. For a long top-quartile and short } \\
\text { bottom-quartile portfolio based on a combination of momentum and value signals we find a } \\
\text { return of 12\% per annum over the 1986-2007 period. Performance is stable over time, also } \\
\text { present in an out-of-sample period and sufficiently high to overcome transaction costs in } \\
\text { practice. The return cannot be explained by potential structural biases towards asset classes } \\
\text { with high risk premiums, nor the Fama French and Carhart hedge factors. We argue that } \\
\text { financial markets may be macro inefficient due to insufficient 'smart money' being available to } \\
\text { arbitrage mispricing effects away. }\end{array}$ \\
\hline Free Keywords & GTAA, value effect, momentum, global asset allocation \\
\hline Availability & $\begin{array}{l}\text { The ERIM Report Series is distributed through the following platforms: } \\
\text { Academic Repository at Erasmus University (DEAR), DEAR ERIM Series Portal } \\
\text { Social Science Research Network (SSRN), SSRN ERIM Series Webpage } \\
\text { Research Papers in Economics (REPEC), REPEC ERIM Series Webpage }\end{array}$ \\
\hline Classifications & $\begin{array}{l}\text { The electronic versions of the papers in the ERIM report Series contain bibliographic metadata } \\
\text { by the following classification systems: } \\
\text { Library of Congress Classification, (LCC) LCC Webpage } \\
\text { Journal of Economic Literature, (JEL), JEL Webpage } \\
\text { ACM Computing Classification System CCS Webpage } \\
\text { Inspec Classification scheme (ICS), ICS Webpage }\end{array}$ \\
\hline
\end{tabular}




\title{
Global Tactical Cross-Asset Allocation:
}

\section{Applying Value and Momentum Across Asset Classes}

\author{
DAVID BLITZ AND PIM VAN VLIET*
}

First version: October 2007

This version: May 2008

* Email: d.c.blitz@robeco.nl and p.van.vliet@robeco.nl. Contact details: Robeco Asset Management, Coolsingel 120, NL-3011 AG Rotterdam, The Netherlands. The authors thank Thierry Post, Laurens Swinkels and an anonymous referee for valuable comments on an earlier version of this paper and Xiaomin Pang for research assistance. 


\begin{abstract}
In this paper we examine global tactical asset allocation (GTAA) strategies across a broad range of asset classes. Contrary to market timing for single asset classes and tactical allocation across similar assets, this topic has received little attention in the existing literature. Our main finding is that momentum and value strategies applied to GTAA across twelve asset classes deliver statistically and economically significant abnormal returns. For a long top-quartile and short bottom-quartile portfolio based on a combination of momentum and value signals we find a return of $12 \%$ per annum over the 1986-2007 period. Performance is stable over time, also present in an out-of-sample period and sufficiently high to overcome transaction costs in practice. The return cannot be explained by potential structural biases towards asset classes with high risk premiums, nor the Fama French and Carhart hedge factors. We argue that financial markets may be macro inefficient due to insufficient 'smart money' being available to arbitrage mispricing effects away.
\end{abstract}


The objective of Global Tactical Asset Allocation (GTAA) is to improve on a given strategic asset allocation by tactically adjusting the weights of asset classes based on their perceived attractiveness. A popular approach to GTAA is to first develop various complementary allocation models, each with a limited scope, that can subsequently be used as building blocks for a comprehensive GTAA strategy. ${ }^{\mathrm{i}}$ For example, one could start with an equity market timing model, and then add a bond market timing model, global country allocation models (both for equities and bonds) and finally a currency allocation model. The next stage entails assigning appropriate risk budgets to each of these models in order to obtain the actual GTAA strategy. For a discussion of a comprehensive GTAA risk budgeting framework, see Sharpe (1987) and Lee (2000). Existing literature provides many useful leads for developing GTAA building-block models. For example, Fama and French [1989] show that factors such as the term spread and dividend yield contain predictive power for the future equity risk premium. The term spread has also been related to future bond returns, for example by Fama and Bliss [1987] and Ilmanen [1995]. For equity country allocation both medium term momentum and long-term mean-reversion have been shown to be effective, see Chan et al. [2000] and Richards [1995, 1997). As a final example we mention carry strategies for currencies, as documented by Hodrick [1987] and Froot and Thaler [1990].

The traditional approach outlined above simplifies the GTAA problem by breaking it down into several smaller problems, which can be handled separately. Each building-block model considers a limited number of similar assets, and can take into account the specific variables that are considered to be relevant for that particular allocation decision. However, by not directly comparing each asset to every other asset in the opportunity set, the full potential of GTAA may be left unrealized. Another drawback of the multi-model approach is that it takes a considerable amount of effort to develop the separate building-block models, which is why in practice often only a limited number of models are actually employed in GTAA strategies. Furthermore, combining the positions indicated by the different models requires a sophisticated risk budgeting approach for managing aggregate portfolio risk. These issues are addressed by the alternative approach to GTAA presented in this paper, which is characterized by the use of a single model to directly compare the attractiveness of a broad and diverse range of asset classes. We call this approach Global Tactical Cross-Asset Allocation, or GTCAA.

The key question which we address is if classic cross-sectional return patterns, which have previously been documented at the security level, can also be observed across asset classes. This topic has received surprisingly little attention in the existing literature. Clearly, if the cross-section of asset class returns cannot be explained by the current set of pricing models, then this would add yet another puzzle to the field of empirical asset pricing. Given that a cross-asset allocation strategy can be implemented relatively easily using a limited number of highly liquid instruments such as futures, finding a profitable GTCAA strategy would pose a formidable challenge to market efficiency.

Using US stock data, Jegadeesh and Titman [1993] document a strong 6-month return momentum effect. Fama and French [1996] show that many US stock market effects can be explained by exposure 
to the size and value premiums, with the exception of 12-1 month momentum. Fama and French [1998] and Rouwenhorst [1998] also document value and momentum premiums for international stock markets. Pirron [2005], one of the few papers which takes a cross-market perspective, reports significant profits for 3 to 12 month price momentum strategies applied to futures markets. Interestingly, mixed results have been found for portfolios based on past 1-month returns. Jegadeesh [1990] finds a short-term reversal effect at the stock level, while Moskowitz and Grinblatt [1999] find a short-term momentum effect at the industry level.

In this paper we examine value and momentum strategies for tactical allocation across a broad range of asset classes. ${ }^{i i}$ Applying price momentum to cross-asset allocation is relatively simple, as this strategy only requires past returns as input. We will consider both a 12-1 month momentum strategy and a strategy based on 1-month returns. Constructing a cross-asset allocation value strategy is less straightforward, as there is no obvious valuation measure which is applicable to every asset class. The essence of our valuation strategy is to compare asset classes using relatively simple yield measures. We describe our approach in detail in the methodology section.

Our main finding is that the application of momentum and value strategies to global tactical asset allocation across twelve asset classes delivers statistically and economically significant abnormal returns. We document return premiums between 7-8\% for the 1-month momentum, 12-1 month momentum and value GTCAA strategies over the 1986-2007 period. Interestingly, the 1-month momentum effect is in line with previous findings at the industry level, and contrary to the reversal effects which are reported at the stock level. For a GTCAA strategy based on a simple combination of momentum and value factors we find an alpha of $12 \%$ per annum. Performance is stable over time, also present for a reduced set of assets over the 1974-1985 period, and sufficiently high to overcome transaction costs in practice. Furthermore, the performance is robust to adjustments for implicit market exposures and is also largely unaffected by adjustments for implicit loadings on the CAPM market factor, the Fama-French size and value factors and the Carhart momentum factor.

Our findings are relevant for both theoretical and practical reasons. From a theoretical perspective our findings may challenge market efficiency and market equilibrium. Furthermore, our results imply that value and momentum effects are not only present within specific asset classes, but also transcend across entire asset classes. Although there is in fact no generally accepted asset-pricing model which applies to the wide variety of asset classes which we consider in this paper, we argue that any such model is unlikely to be able to explain the return effects which we find in our analysis. Interestingly, the momentum and value effects which we observe across different asset classes are similar in magnitude, but at most partly related to the momentum and value effects that have previously been documented within asset classes and for which behavioral explanations have been put forward. Inspired by these, we also provide a possible behavioral explanation for the momentum and value effects which we observe across asset classes. 
For practitioners our results are interesting because they provide a single-model approach to GTAA, which may be used as either an alternative to multi-model GTAA strategies, or as an additional building block for such strategies. One of the limitations of our cross-asset allocation approach is that it cannot easily incorporate asset-specific variables. For example, analysts' earnings revisions might be a relevant factor for equity markets, but bond markets lack an obvious equivalent measure. Hence, with GTCAA the focus is more on breadth (covering many assets with a limited set of factors) than on depth (covering a single allocation decision with many asset-specific factors).

The remainder of this paper is organized as follows. In the next section we first describe the data and methodology. Next we present our main results for momentum and valuation strategies applied to Global Tactical Cross-Asset Allocation. The subsequent section contains various robustness tests. This is followed by a discussion of possible explanations for our findings. We end with conclusions and implications for investors.

\section{Data and methodology}

Exhibit 1 gives an overview of the asset classes that constitute the opportunity set for our analyses and the indices that we use to measure the returns of these asset classes. The total number of asset classes is twelve. Three of these relate to the US equity market, namely US large-cap equities, US mid-cap equities and US real estate equities (REITS). We also include three international equity markets, specifically the UK, Japan and emerging markets. Three US bond asset classes are included, namely US Treasuries, US investment grade bonds and US high yield bonds. In addition we include the two main international bond markets, Germany and Japan. The final asset is a US 1-month LIBOR cash investment, which serves as our proxy for the risk-free alternative.

\section{[INSERT EXHIBIT 1]}

Although the selection of these asset classes was not based on a formal set of rules, we did take into consideration a number of criteria, in particular for which asset classes not to include:

- $\quad$ asset classes for which less than twenty years of data history is available, e.g. emerging debt and hedge funds;

- asset classes which are more difficult to model, especially with regard to valuation, e.g. commodities and currencies;

- asset classes which are illiquid and/or lack market prices, e.g. direct real estate and private equity;

- asset classes with a limited market capitalization and/or limited economic relevance, e.g. microcap stocks;

- asset classes which are highly correlated and would reduce the heterogeneity of the investment universe, e.g. the inclusion of each of the twenty largest stock markets as separate assetsiii 
For each asset class, except emerging markets equities, we take total returns in local currency and subtract the local risk free return, i.e. US, UK, Japan or German 1-month LIBOR. These excess returns resemble the returns that can be obtained in practice with futures contracts, although it should be noted that these are (or were) not actually available in practice for all assets. ${ }^{\text {iv }}$ For emerging markets equities we take open (unhedged) returns in US dollars in excess of the US 1-month LIBOR return.

The earliest date for which return data is available for every asset class in our universe is January 1985. Because 12-1 month momentum is among the strategies that we want to analyze, our analysis effectively starts at the end of January 1986. This is actually also the first month for which valuation data is available for every asset class. The last month of our sample period is September 2007. Exhibit 2 summarizes the risk and return characteristics of each asset class over the full sample period. Average annual excess returns vary between less than 1\% (for Japan equity) and almost 11\% (for emerging markets equity). Sharpe ratios for the individual asset classes vary between 0.03 (again for Japan equity) and 0.56 (for US investment grade bonds).

\section{[INSERT EXHIBIT 2]}

At the end of every month we rank all assets based on their momentum and/or valuation scores, and use this ranking to assign the assets to four quartile portfolios consisting of three assets each. We then calculate the return of each quartile portfolio over the following month. In addition to the four longonly quartile portfolios we also consider a long top-quartile and short bottom-quartile zeroinvestment portfolio. This process is repeated until the end of the sample period. Transaction costs are not included in the initial strategy evaluation, but are discussed separately in a sensitivity analysis.

Our methodology is consistent with classic empirical studies of cross-sectional return patterns at the security level. The fact that our long/short portfolio effectively consists of three pair trades is also conceptually consistent with the theoretical result in Lee (2000), that optimal bet sizes in TAA strategies are directly driven by the pairwise differences in expected returns of assets. ${ }^{v}$ Our pair trades may consist of traditional TAA bets, such as long US large-cap equities and short US Treasuries, but they can also be less conventional, such as long US real estate equities and short Japanese government bonds. Instead of a weakness this may actually be a strength of our cross-market approach. In the discussion section we will argue that inefficiencies may arise at the level of asset classes, because many investors perceive full-fledged global tactical asset allocation to be too challenging. We also note that when stand-alone long/short timing strategies are applied to the individual assets within a broadly diversified strategic allocation ${ }^{\mathrm{vi}}$, the net outcome may well consist of some unconventional pair trades.

We will examine both a 1-month return strategy and a classic 12-1 month (12 months excluding the most recent month) momentum strategy. Only return data is required for these analyses. In addition to the two momentum strategies we also consider a cross-asset valuation strategy. This strategy is less straightforward, as it requires valuation data that can be used for making direct cross-sectional 
comparisons of asset classes. The starting point of our approach is to take a simple yield measure for each asset class. For equity assets we take the (trailing) earnings yield (E/P ratio), while for bond assets we take the standard yield-to-maturity. vii Both yield measures are adjusted for the appropriate (local) risk-free rate of return, as shown in the third column of Exhibit 3. Note that for the bond assets this means that we are effectively taking the term premium as our valuation indicator.

\section{[INSERT EXHIBIT 3]}

The simplicity of using these basic yield measures is appealing, but it is questionable if sensible comparisons of different asset classes can be made with such an elementary approach. Indeed, it is not difficult to illustrate that this approach is overly simplistic and needs to be refined. Consider for example the yield on US high yield bonds versus that on comparable US Treasury bonds. Obviously, the difference should always be positive, as investors require a compensation for being exposed to default risk. Thus, an adjustment for default risk should be made in order to prevent US high yield bonds from being structurally preferred to US Treasuries. Without such an adjustment, US high yield bonds would in fact end up in the top quartile value portfolio $93 \%(!)$ of the time. For other assets the need for an adjustment to the basic yield measure might be less obvious at first sight, but equally necessary. For example, yields on government bonds are not necessarily directly comparable to those on stocks.

For our valuation strategy we apply a limited number of asset-specific, fixed adjustments to the basic yield data. These adjustments were chosen in such a way that the main structural biases towards certain asset classes are removed. Specifically:

- for the government bond assets, US Treasuries and German and Japanese government bonds, we subtract $1 \%$ from the term premiums, which adjusts for the fact that the yield curve tends to be upward sloping;

- for US investment grade credits we subtract $2 \%$ and for US high yield bonds $6 \%$, also to adjust for the slope of the yield curve, and additionally to adjust for default risk;

- for emerging markets equities we subtract $1 \%$ to adjust for the structurally lower P/E compared to mature equity markets;

- for US real estate equities we subtract $2 \%$ to adjust for the structurally higher yield compared to regular equities.

By comparing the average valuation scores before and after these adjustments, shown in the secondto-last and last columns of Exhibit 3, it can be seen that these adjustments result in scores that are much more comparable across asset classes. In fact, after applying the adjustments, the long-term average valuation score for every asset falls in a range between $-1 \%$ and $+1 \%$, which implies that structural biases towards certain asset classes are effectively eliminated.viii

Given the valuation scores, the valuation investment strategy is tested in a similar way as the momentum strategies discussed earlier, i.e. based on quartile portfolios with a monthly rebalancing frequency. To better understand the interaction between the valuation and momentum effects, we also 
analyze a combined investment strategy. A combined score for each asset class is calculated by taking a weighted average of its rank (1 to 12) on the individual variables. We choose for a simple 50/50 balance between the momentum and valuation strategies and equal weighting of the two momentum variables. This translates into weights of $25 \%$ for 1-month momentum, 25\% for 12-1 month momentum and $50 \%$ for valuation. ${ }^{\text {ix }}$ The correlation structure between the three underlying strategies, which is discussed in the next section, provides an additional motivation for this choice of weights.

\section{Main results}

The main results of our analysis are presented in Exhibit 4. The top (first) quartile portfolios for the 1month momentum, 12-1 month momentum and valuation strategies can be seen to generate relatively high returns and Sharpe-ratios, while the bottom (fourth) quartile portfolios are associated with the lowest returns and Sharpe ratios. The second and third quartile portfolios tend to fall neatly in between, resulting in a monotonic performance pattern over the four quartile portfolios. The long topquartile and short bottom-quartile (Q1-Q4) zero-investment portfolio generates positive annualized returns of $6.9 \%$ for 1 -month momentum, $7.9 \%$ for $12-1$ month momentum and $7.9 \%$ for valuation, which are all statistically significantly different from zero at the $1 \%$ significance level. Interestingly, the 1-month momentum effect is in line with previous findings at the industry level, and contrary to the reversal effects which are reported at the stock level. Furthermore, the GTCAA 12-1 month momentum effect is similar in magnitude to the US stock market momentum effect (UMD, 8.4\% during our sample), while the GTCAA value effect is even larger than the value effect within the US stock market (HML, 3.4\% during our sample). We conclude that all three variables exhibit significant predictive power for Global Tactical Cross-Asset Allocation purposes.

\section{[INSERT EXHIBIT 4]}

The two momentum strategies exhibit a positive correlation of 0.3 with each other, and negative correlations of -0.1 to -0.3 with the valuation strategy. These relatively low correlations indicate that we are capturing three distinct effects. The correlation structure also provides an additional motivation for our choice of weights in the combined strategy, as it makes sense to reduce the weight of variables that are positively correlated (the two momentum variables) and increase the weight of variables that exhibit negative correlations (valuation). Given the relatively low correlations it is not surprising that the performance of the combined strategy is superior to each of the underlying strategies. The top-quartile portfolio for the combined strategy outperforms the top-quartile portfolios of the underlying strategies, and for the bottom-quartile portfolio of the combined strategy we find the lowest returns so far. This results in a return of $11.9 \%$ per annum for the long/short combined strategy, which is highly significant with a t-statistic of well over 5 . The volatility of the strategy is $10 \%$, somewhere between equity and bonds, which results in an information ratio of 1.2. Exhibit 5 shows the cumulative returns for both the combined and the individual strategies over time. 
Performance can be seen to be quite stable over time, and is, for example, not just concentrated in the early years of the sample.

\section{[INSERT EXHIBIT 5]}

Next we examine if perhaps the returns of the strategies might be explained by structural biases towards certain asset classes. If we consider for example a naïve portfolio which goes systematically long in equities and short in cash, then the return which is captured by this portfolio simply reflects the equity risk premium. Thus, our concern is that the quartile portfolios may have structurally different exposures to the risk premiums that are offered by the various asset classes. The importance of adjusting for such structural biases is also stressed by Lee (2000). For the combined strategy we therefore look at the frequency with which each asset class is selected for each of the quartile portfolios. In Exhibit 6 it can be seen that the asset class which is selected most frequently in the topquartile portfolio is US real estate equities (REITS), while UK equities tend to be the least favorite asset class. We also observe that each asset class occurs in each of the quartile portfolios for at least $3 \%$ of the observations, and no asset class occurs in any quartile portfolio for more than $43 \%$ of the time. ${ }^{x}$ This indicates that the combined value-momentum GTCAA strategy does not have a large structural bias towards one specific asset class.

\section{[INSERT EXHIBIT 6]}

More formally, we calculated for each portfolio its average net exposure to each of the twelve asset classes, i.e. measured ex-post over the entire sample period. Using these weights we can create static reference portfolios which, by definition, exhibit the same average exposures to the various asset classes as the original portfolios. By subtracting the returns of these reference portfolios from the returns of the original portfolios, we thus effectively adjust the latter for possible systematic biases towards certain asset classes. The Q1-Q4 return of the combination strategy remains at $11 \%$, again with a highly significant $t$-statistic larger than 5 . Thus, we can conclude that the results are generally robust to the adjustments for implicit systematic biases towards certain asset classes.

In Exhibit 7 we adjust the (raw) GTCAA strategy returns for their implicit loadings on the classic CAPM market factor, the Fama French size and value factors and the Carhart momentum factor. ${ }^{x i}$ These regressions allow us to determine if the GTCAA momentum and valuation returns are unique effects, or simply a cross-asset manifestation of effects that are already known to exist within the US stock market.

\section{[INSERT EXHIBIT 7]}

Exhibit 7 shows that a CAPM adjustment does not materially affect the returns of the strategies. The value strategy has a negative loading on the CAPM market factor, while the 12-1 month momentum strategy has a positive beta with regard to the market factor, but these exposures do not subsume their 
returns. The alphas also remain strong when the Fama French 3-factor adjustment is applied. An interesting observation is that the GTCAA valuation strategy appears to be weakly related to the Fama French value (HML) and size (SMB) factors. The loading on HML suggests that the GTCAA value effect is, to a limited degree, related to the classic value effect within the US stock market. Apparently this relationship is not very dominant though, as the alpha of the GTCAA valuation strategy only drops by about $1 \%$. The same observations apply to the GTCAA combination strategy.

The Fama French / Carhart 4-factor adjustments reveal that the 12-1 month momentum strategy is strongly related to the 12-1 month stock momentum factor (UMD). The GTCAA 12-1 month momentum alpha is in fact subsumed to a large degree and becomes insignificant after adjusting for the UMD momentum factor. Thus, the 12-1 momentum GTCAA strategy is picking up a cross-asset allocation momentum effect which is closely related to the well-known momentum effect within the US stock market. xii As both UMD and the cross-market 12-1 month momentum strategy earn premiums of $8 \%$ during our sample period, one could also argue that UMD can be mimicked with our cross-market 12-1 month momentum strategy. This is an interesting observation, because the UMD momentum premium is difficult to capture in reality, as it involves frequent trading in many hundreds of individual stocks. Our cross-market strategy, on the other hand, involves only twelve highly liquid asset classes and is thus a much easier strategy in practice. The GTCAA 1-month momentum strategy is not affected by a UMD correction.

Interestingly, the GTCAA valuation strategy exhibits a strong negative loading on the momentum factor, which strengthens its 4-factor alpha. For the GTCAA combined strategy these effects turn out to offset each other, as in this case the effective exposure to the momentum factor is insignificant. As a result, the alpha of the GTCAA combined strategy is robust to CAPM, 3-factor and 4-factor model adjustments and remains very strong at $11-12 \%$ per annum.

\section{Robustness tests}

In this section we further examine the robustness of our findings. First we analyze the impact of transaction costs. For this we begin by calculating the amount of turnover that is associated with the Q1-Q4 strategies. The maximum annual (monthly) turnover is $2400 \%$ (200\%) one-way, in the event that all long and short positions would be replaced every month. xiii Exhibit 8 shows that the annual turnover varies from about $200 \%$ for the valuation strategy to $1600 \%$ for the 1 -month momentum strategy. In order to translate the turnover figures into an estimate of annual transaction costs, we need to assume a certain level of transaction costs for individual trades. Instead of choosing one particular level of transaction costs per trade we will consider three different levels: $10 \mathrm{bp}, 25 \mathrm{bp}$ or, most conservatively, $50 \mathrm{bp}$. The $10 \mathrm{bp}$ figure represents a realistic estimate in case the strategies could be implemented using highly liquid instruments such as futures. As this assumption may be too optimistic, especially historically, we also consider the more conservative transaction cost levels. 


\section{[INSERT EXHIBIT 8]}

Exhibit 8 shows estimated returns after transaction costs for the Q1-Q4 strategies. Comparing these to the results before costs in Exhibit 4 it is clear that transaction costs are critical for the high turnover 1month momentum strategy. At a cost level of $10 \mathrm{bp}$ about half the performance of this strategy is lost, while performance is completely wiped out if costs are assumed to be more than $20 \mathrm{bp}$ per trade. Not surprisingly, the slower 12-1 month momentum and valuation strategies are less sensitive to transaction costs. For example, at costs of $25 \mathrm{bp}$ per trade, a third of the performance of the 12-1 month momentum strategy is lost and only about $15 \%$ of the performance of the valuation strategy. The combined strategy is well able to survive a realistic level of transaction costs, as even with transaction costs of 50 bp per trade an outperformance of $5 \%$ per annum remains. We also note that it is likely that the return can be improved significantly in practice by considering more sophisticated buy/sell rules, or a portfolio optimization which (a.o.) is able to trade off gross expected returns against the transaction costs associated with trading. These extensions are beyond the scope of this paper however. We conclude that a GTCAA strategy can generate sufficient performance to overcome the transaction costs that would be incurred in a real-world implementation.

A second robustness test is a pre-sample test on the period from January 1974 to January 1986. Unfortunately data for the last four asset classes in Exhibit 1, emerging markets equities, US high yield bonds, German government bonds and Japanese government bonds, are not available over this period. As a result, the number of asset classes drops to eight, and each quartile portfolio consists of only two instead of three asset classes. Exhibit 9, which is similar in structure to Exhibit 4, shows that the returns of the various GTCAA strategies tend to be somewhat lower, but still strong over this out-ofsample period.

\section{[INSERT EXHIBIT 9]}

In a third robustness test we look at the effects of using asset class returns that are adjusted for their volatility. Obviously, some assets exhibit much more volatility than others. As a result, the returns of equally weighted portfolios of assets could be dominated by the positions taken in the most volatile assets, such as emerging markets equities. The most volatile assets are also most likely to be either most attractive or least attractive on a measure such as momentum, as these assets tend to produce the most extreme returns. In order to avoid these effects we apply asset-specific volatility adjustments which are intended to make the asset classes more comparable. ${ }^{\text {xiv }}$ Specifically, at the end of every month we take for each asset its annualized volatility over the past 60 months, and use this to lever or de-lever the position in that asset over the next month to an (arbitrary) target volatility level of $10 \% .{ }^{x v}$ For example, if the trailing volatility of emerging markets equities is $20 \%$, versus only $5 \%$ for US Treasuries, we take half the regular position in emerging markets equities and double the regular position in US Treasuries. Exhibit 10 shows that the results for this approach remain strong. The Q1Q4 return for the momentum and valuation strategies on a stand-alone basis is in the $4-7 \%$ range, while for the combined strategy it is about $9 \%$. Although at first sight this appears to be lower than for 
the original strategy, the volatility that is associated with the alternative approach is somewhat lower as well. As a result, both approaches exhibit the same information ratio of 1.2. Thus, the results are clearly robust to the methodological choice of whether or not it is appropriate to adjust asset returns for their volatility.

\section{[INSERT EXHIBIT 10]}

A final concern which we address is whether the return of the cross-asset allocation strategies might be driven by just one or only a few asset classes. However, the strategy also passes this robustness test without problems. Exhibit 11 shows for each asset class the average monthly return conditional on its quintile classification in the combined strategy. It can be seen that most asset classes earn an average excess return of at least $0.3 \%$ during the months that they are top ranked, with a median of $0.8 \%$ across the different asset classes. During the months of being bottom ranked every asset class, with the only exception of US mid-cap equities ${ }^{x v i}$, earns an average excess return of at most $0.2 \%$, with a median of zero. Based on these results we can conclude that the valuation and momentum effects are driven by all asset classes and clearly not by only one or a few.

\section{[INSERT EXHIBIT 11]}

\section{Discussion}

We continue by discussing possible explanations for our empirical finding that simple momentum and valuation strategies seem highly effective for Global Tactical Asset Allocation across asset classes. It might be that our findings are simply the result of chance or overenthusiastic data mining. In that case the relationships which we have documented would most likely break down in the future, and the alpha opportunity would turn out to be an illusion. Although impossible to rule out we do not consider this explanation to be likely, because the strategies analyzed in this paper are very basic by design and at the same time the statistical significance of the results is quite strong.

Another explanation for our findings might be that we are capturing time-varying risk premiums on the different asset classes and/or that we are not properly adjusting the strategy returns for risk. For example, suppose each asset class can be in either a state of high expected return combined with high risk, or in a state of low expected return and low risk. A strategy which implicitly goes long in assets that tend to be in the high risk state and short assets that tend to be in the low risk state might then seem to be capturing alpha, while in fact the returns that are being generated simply represent a fair compensation for risk. Again we cannot rule out this explanation, but we argue that it also seems unlikely. We begin by noting that the degree of time-variation in risk of the asset classes would have to be quite large in order to justify a return spread of $12 \%$ per annum which we found for the combined strategy. The results are in fact so strong that for the bottom-quartile portfolios we find long-term excess returns that are close to zero or even negative, whilst even time-varying risk 
premiums ought to remain positive at all times. Furthermore, there is no evidence of increased risk for the high-return top-quartile portfolio of assets compared to the low-return bottom-quartile portfolio, in terms of volatility, skewness and other measures (statistics not reported). In Exhibit 12 we look at the return of the GTCAA strategies conditional on different macro-economic regimes. For this analysis we used the VIX level, term spread, credit spread and interest rate level as regime indicators. ${ }^{x v i i}$ The results are not consistent with a time-varying risk explanation of our results, as alpha spreads are positive in all states-of-the-world. For example, the valuation premium does not depend on VIX or term spread, although it does seem to be higher during periods with low interest rates and low credit spreads, such as for example during the 2003-2006 period. Both our momentum strategies also show no clear link to economic states-of-the-world. For the combined strategy we also do not find an obvious relation between the economic environment on the one hand and the returns of the GTCAA strategy on the other.

\section{[INSERT EXHIBIT 12]}

If all the explanations that have been put forward above are inadequate, then we are left to consider the possibility that our results may represent a new asset pricing puzzle which challenges market efficiency and market equilibrium. Unfortunately, the concept of market efficiency in the context of GTAA is not well-defined, because there is no generally accepted asset-pricing model which applies to the wide variety of asset classes that are covered in our study. Interestingly, the momentum and value effects which we observe across different asset classes are conceptually similar to the effects that have previously been documented within asset classes or at the level of individual asset-classes and for which behavioral explanations have been put forward. This raises the question as to whether the momentum and value effects which we observe across asset classes might also be capturing inefficiencies caused by behavioral effects and are thus posing a challenge to market efficiency. Inefficiencies at the level of asset-classes might be caused by too little 'smart money' being available to actively arbitrage inefficiencies away as soon as they occur. We provide two lines of reasoning which support this hypothesis.

First, many investors may want to refrain from aggressive broad tactical cross-asset allocation simply because they perceive this to be too challenging. As noted earlier, we lack a solid theoretical framework for pricing the heterogeneous set of asset classes covered in our analysis, which means that there is a large degree of uncertainty surrounding the fair valuations of these asset classes. For example, even though empirically we find that our GTCAA valuation strategy is effective, we do not believe that in equilibrium every asset really ought to be valued according to the simple valuation measures which we used in that particular strategy.

Second, most professional market participants such as fund managers and analysts focus on allocation and security selection within a certain asset class. For example, a high yield bond manager tends to focus on picking the best high yield bonds and is usually not particularly concerned about the attractiveness of high yield bonds as an asset class compared to for example REITS. Instead, allocation 
decisions across asset classes tend to be made primarily by end-investors such as pension fund boards and individuals. Their behavior may be primarily driven by factors such as:

- long-term considerations, e.g. adhering to a strategic mix which follows from an asset-liability management study;

- fixed allocation mechanisms, e.g. the use of a pre-specified asset allocation mix for cash inflows (e.g. 401K plan contributions) throughout a year;

- herding behavior, i.e. not wanting to deviate too much from the peer group;

- recent performance of an asset class, as considerably more money tends to flow into 'hot' asset classes which have recently exhibited strong performance than into asset classes with mediocre or disappointing returns.

Following this reasoning it is not hard to imagine that mispricing effects may arise at the level of asset classes. Furthermore, this would also suggest that these effects are likely to persist going forward, at least until more 'smart money' becomes available to actively arbitrage away this opportunity for alpha.

Hedge funds constitute a natural source for this 'smart money', as these funds have the flexibility to take advantage of alpha sources that are ignored by many traditional managers. A priori we would expect managed-futures and global-macro style hedge funds to be particularly likely candidates for engaging in GTCAA type of strategies. In order to investigate whether hedge funds are indeed trying to exploit GTCAA alphas we regress the GTCAA strategy returns on hedge fund returns. The results, shown in Exhibit 13, provide a mixed picture.

\section{[INSERT EXHIBIT 13]}

On the one hand, we observe that the returns of certain hedge funds do indeed appear to be related to our GTCAA strategies. However, this is mainly driven by exposures to the GTCAA 12-1 month momentum strategy, which we have seen to be strongly related to momentum at the stock level, such as the UMD effect. The GTCAA 1-month momentum and value strategies appear to be considerably less popular among hedge funds, as we find only one positive and significant $t$-statistic for each of these strategies. For 'global macro', one of our most likely 'smart money' candidates, we even find a significantly negative relation with our GTCAA valuation strategy. Perhaps this is due to the fact that the horizon which is required for this strategy is too long for funds that are strongly focused on shortterm performance. More negative exposures are found for other hedge fund styles, and we even find a negative relation between the combined strategy and the aggregate CSFB/Tremont hedge fund index. Thus, we conclude that although some hedge funds may indeed be trying to exploit some of the crossmarket allocation alphas documented in this paper, the overall results do not indicate that this is occurring at the large scale which would be needed to arbitrage away all these effects.

\section{Summary, implications and extensions}


We find statistically and economically significant return premiums between 7-8\% for 1-month momentum, 12-1 month momentum and value GTCAA strategies over the 1986-2007 period. For a GTCAA strategy based on a simple combination of momentum and value factors we find an alpha of $12 \%$ per annum. Our findings are not only relevant for practitioners, but also theoretically, as they show that effects which have previously been documented to exist within asset classes can also be observed across entire asset classes. However, we are not simply capturing known effects in a new way, as the combined strategy returns in particular remain strong after adjusting for implicit loadings on for example the Fama French value and Carhart momentum factors. Thus, although being similar in spirit, the cross-asset effects do in fact constitute different return irregularities. This adds yet another puzzle to the field of empirical asset pricing and a challenge to market efficiency.

We have provided several arguments against risk-based explanations for our findings. Instead, we argue that financial markets may be macro inefficient due to insufficient 'smart money' being available to arbitrage away mispricing effects that may arise due to behavioral effects. Certain types of hedge funds might be expected to represent this 'smart money' and be likely candidates to take advantage of the cross-asset allocation alphas in practice. Although we find some evidence which seems to be consistent with this, other evidence point at behavior which is in fact contrary to our GTCAA strategies.

Our results may be extended in several ways. One direction for follow-up research would be to expand the number of asset classes that is covered by the strategy, for example by adding asset classes for which only a shorter data history is available (e.g. emerging debt, hedge funds), which are more difficult to model (particularly with regard to valuation, e.g. commodities and currencies) or which are less liquid and/or lack market prices (e.g. direct real estate and private equity). A second way of extending the research would be to analyze more potential predictor variables. Variables that are not asset-class specific may be particularly interesting in this regard. For example, Jensen, Mercer and Johnson [1996, 2002] relate monetary conditions to future stock returns and future commodity returns. Calendar and seasonal indicators, such as January or winter/summer effects might be useful as well, or macro-economic indicators, such as consumer and producer confidence, interest rate changes, oil price movements, etc. Thirdly, some form of portfolio optimization might be introduced in order to try to further improve risk-adjusted returns. For example, the simple ranking method used in this paper ignores correlations between the assets that are selected and may thus be suboptimal. By expanding the number of assets, by finding new alpha factors and/or by more advanced portfolio construction the case for Global Tactical-Cross Asset Allocation might be strengthened further.

\section{References}

Chan, K., Hameed, A. \& Tong, W. (2000), Profitability of momentum strategies in the international equity markets, Journal of Financial and Quantitative Analysis, 35(2), p. 153-172 
Fama, E.F. \& Bliss, R.R. (1987), The information in long-maturity forward rates, American Economic Review, 77, p. 680-692

Fama, E.F. \& French, K.R. (1989), Business conditions and expected returns on stocks and bonds, Journal of Financial Economics, 25, p. 23-49.

Fama, E.F. \& French, K.R. (1996), Multifactor explanations of asset pricing anomalies, Journal of Finance, 51(1), p. 55-84.

Fama, E.F., \& French, K.R., (1998), Value versus growth: the international evidence, Journal of Finance, 53(6), p. 1975-1999

Froot, K.A. \& Thaler, R.H. (1990), Foreign exchange, Journal of Economic Perspectives, 4 (3), Summer, p. 179-192

Hodrick, R.J. (1987), The empirical evidence on the efficiency of forward and futures foreign exchange markets, Harwood, London

Ilmanen, A. (1995), Time varying expected bond returns in international bond markets," Journal of Finance, 50(2), p. 481-506

Jegadeesh, N. (1990), Evidence of predictable behavior of security returns, Journal of Finance, 45(3), p. $881-898$

Jegadeesh, N., Titman S. (1993), Returns to buying winners and selling losers, implications for stock market efficiency, Journal of Finance, 48(3), p. 65-91

Jensen, G.R., Mercer, J.M. \& Johnson, R.R. (1996), Business conditions, monetary policy, and expected security returns, Journal of Financial Economics, 40(2), p. 213-237

Jensen, G.R., Mercer, J.M. \& Johnson, R.R. (2002), Tactical asset allocation and commodity futures, Journal of Portfolio Management, Summer, p. 100-111

Lee, W. (2000), Theory and methodology of tactical asset allocation, John Wiley \& Sons

Moskowitz, T.J. \& Grinblatt, M. (1999), Do industries explain momentum?, Journal of Finance, 54(4), p. $1249-1290$

Pirrong, C., (2005), Momentum in futures markets, working paper, SSRN abstract 671841 
Richards, A.J. (1995), Comovements in national stock market returns: Evidence of predictability, but not cointegration, Journal of Monetary Economics, 36, p. 631-654.

Richards, A.J. (1997), Winner-loser reversals in national stock market indices: Can they be explained?, Journal of Finance, 52, p. 2129-2144.

Rouwenhorst, K.G., (1998), International momentum strategies, Journal of Finance 53(1), 267-284

Sharpe, W.F., (1987), Integrated Asset Allocation, Financial Analyst Journal, September/October, p. 2532

\section{Endnotes}

i Goldman Sachs is an example of a well-known GTAA provider using this approach, see for example http://www2.goldmansachs.com/client_services/asset_management/institutional/pdf/global_tactical.pdf. ii We did not attempt to test for a GTCAA size effect. A priori we do not expect to find a size effect across asset classes, as the size of an asset class is not a straight reflection of the economic size of the underlying securities, but also depends on the breadth of that asset class, i.e. the number of different securities.

iii In this way we also avoid that our universe is basically an equity country allocation universe (for which a lot of research is already available) 'plus a few other assets'.

iv Nowadays, markets are more liquid and more instruments are available than in the earlier part of the sample. For example, besides futures, OTC swaps or ETFs may constitute efficient alternative instruments for efficiently gaining exposure during the latter part of the sample.

$\checkmark$ By additionally taking into account the covariance matrix of asset returns the full potential of TAA can be unlocked. We partly address this issue in the sensitivity analysis where we use volatility adjusted bet sizes instead of equal bet sizes.

vi The specific strategic asset allocation of an investor will actually be ignored in our analysis, based on the finding in Lee (2000) that when tactical asset allocation is approached from a portable alpha perspective, the optimal tactical bets are entirely independent of the underlying benchmark portfolio.

vii As earnings yield data is unfortunately not available for US real estate equities, we decided to use dividend yield data instead for this asset class. This is actually not a bad approximation, as REITS are legally obliged to distribute at least $90 \%$ of their income as dividends.

viii The price which we have to pay for obtaining a more reasonable value strategy without structural biases is that our adjustments introduce a look-ahead bias, because in the past an investor might have considered certain alternative adjustment levels to be more appropriate. However, we also find strong results (not reported) for an alternative valuation strategy which is free of look-ahead bias. This approach consists of normalizing the valuation level of an asset class by adjusting for its own historical average. Disadvantages of this alternative approach are that it is more data intensive (as a result of which the sample period is shortened) and the introduction of another kind of ambiguity (which lookback period, different adjustments for similar assets, etc.).

ix In order to avoid occasional ties we actually give a $25.01 \%$ weight to the $12-1$ month momentum variable. We choose to give a little bit more weight to the slower momentum factor in order to limit turnover.

$x$ The same is actually true for each of the three underlying strategies.

xi The data for this analysis was taken from the Kenneth French website. 
xii This finding differs from the cross-market momentum results of Pirrong (2005), who also performed a fourfactor correction which did not significantly affect the alpha. This might be attributed to differences in the universe of assets and/or sample period.

xii In practice transaction costs might be reduced significantly by applying more advanced buy and sell rules. For example, an asset which drops from rank three (out of twelve) to four falls out of the top quartile and is thus replaced in the Q1-Q4 portfolio. However, given the fact that the change in ranking is only one notch and given that the second-quartile portfolio also outperforms, it may in fact be more attractive to hold on to the position in such an asset on an after-cost basis.

xiv Except the risk-free asset, because this has zero volatility.

xv Note that for some asset classes there is insufficient return history for the initial years of the sample. In such cases we use volatilities calculated over the first 60 months of the series instead. This introduces a slight lookahead bias, but in our view not a serious one as volatility is used only as a scaling factor.

xvi Further analysis reveals that 12-1 month momentum is the main culprit for the weak performance of the strategy on US mid-cap equity.

xvii The data are obtained from the St. Louis Federal Reserve. The VIX is the implied volatility on 1-month S\&P 100 / 500 index options, the term spread is defined as the difference between 10 year and 1 year US Treasury yields, the credit spread is the difference between Baa and Aaa corporate bond yields and the interest rate level is the 30-day T-bill rate. 
Exhibit 1: Indices used

\begin{tabular}{llc}
\hline Asset class & Index & Start date \\
\hline US large-cap equity & S\&P 500 (prior to 1988: Datastream calculated) & jan-70 \\
US mid-cap equity & S\&P 400 Datastream calculated & feb-73 \\
US real estate equity & FTSE/NAREIT & feb-72 \\
UK equity & FTSE 100 (prior to 1986: MSCI UK) & feb-73 \\
Japan equity & TOPIX & feb-73 \\
US Treasury bonds & Lehman US Treasury & feb-73 \\
US investment grade bonds & Lehman US Corporate investment grade & jan-70 \\
Cash (risk-free) & 1M LIBOR & Jan-85* \\
Emerging markets equity & S\&P/IFC Investable Emerging Markets & jan-80 \\
US high yield bonds & Lehman US High Yield (prior to 1987: Merrill Lynch High Yield 175) & jan-85 \\
German government bonds & Citigroup government bond Germany & jan-85 \\
Japan government bonds & Citigroup government bond Japan &
\end{tabular}

* Prior to 1989: S\&P/IFC Global Emerging Markets. Valuation data for emerging markets equity starts in Jan-86 
Exhibit 2: Risk/return characteristics, based on annualized excess returns, sample period February 1986 through September 2007

\begin{tabular}{lccc}
\hline Asset class & Geometric mean & Standard deviation & Sharpe-ratio \\
\hline US large-cap equity & $6.6 \%$ & $14.8 \%$ & 0.45 \\
US mid-cap equity & $6.7 \%$ & $15.6 \%$ & 0.43 \\
US real estate equity & $5.3 \%$ & $12.9 \%$ & 0.41 \\
UK equity & $3.5 \%$ & $15.6 \%$ & 0.22 \\
Japan equity & $0.7 \%$ & $19.6 \%$ & 0.03 \\
US Treasury bonds & $2.1 \%$ & $4.7 \%$ & 0.44 \\
US investment grade bonds & $2.7 \%$ & $4.9 \%$ & 0.56 \\
Cash (risk-free) & $0.0 \%$ & $0.0 \%$ & n.a. \\
Emerging markets equity & $10.8 \%$ & $23.0 \%$ & 0.47 \\
US high yield bonds & $3.4 \%$ & $7.3 \%$ & 0.47 \\
German government bonds & $1.4 \%$ & $3.3 \%$ & 0.43 \\
Japan government bonds & $2.2 \%$ & $4.0 \%$ & 0.55 \\
\hline
\end{tabular}


Exhibit 3: Valuation measures

\begin{tabular}{lccccc}
\hline Asset class & Valuation measure & Reference point & $\begin{array}{c}\text { Average without } \\
\text { extra hurdle }\end{array}$ & $\begin{array}{c}\text { Extra } \\
\text { hurdle }\end{array}$ & $\begin{array}{c}\text { Average with } \\
\text { extra hurdle }\end{array}$ \\
\hline US large-cap equity & E/P & US 1M LIBOR rate & $-0.2 \%$ & - & $-0.2 \%$ \\
US mid-cap equity & E/P & US 1M LIBOR rate & $0.6 \%$ & - & $0.6 \%$ \\
US real estate equity & D/P & US 1M LIBOR rate & $2.5 \%$ & $2 \%$ & $0.5 \%$ \\
UK equity & E/P & UK 1M LIBOR rate & $-1.0 \%$ & - & $-1.0 \%$ \\
Japan equity & E/P & Japan 1M LIBOR rate & $-0.2 \%$ & - & $-0.2 \%$ \\
US Treasury bonds & Yield & US 1M LIBOR rate & $0.9 \%$ & $1 \%$ & $-0.1 \%$ \\
US investment grade bonds & Yield & US 1M LIBOR rate & $2.2 \%$ & $2 \%$ & $0.2 \%$ \\
Cash (risk-free) & 1M LIBOR & US 1M LIBOR rate & $0.0 \%$ & - & $0.0 \%$ \\
Emerging markets equity & E/P & US 1M LIBOR rate & $0.9 \%$ & $1 \%$ & $-0.1 \%$ \\
US high yield bonds & Yield & US 1M LIBOR rate & $6.2 \%$ & $6 \%$ & $0.2 \%$ \\
German government bonds & Yield & German 1M LIBOR rate & $0.7 \%$ & $1 \%$ & $-0.3 \%$ \\
Japan government bonds & Yield & Japan 1M LIBOR rate & $0.6 \%$ & $1 \%$ & $-0.4 \%$ \\
\hline
\end{tabular}


Exhibit 4: Main results for value, momentum and combination strategies, annualized log excess returns, sample period February 1986 through September 2007

\begin{tabular}{|c|c|c|c|c|c|c|}
\hline & Q1 & Q2 & Q3 & Q4 & & Q1-Q4 \\
\hline \multicolumn{7}{|l|}{1 month momentum } \\
\hline Mean return & $9.9 \%$ & $3.9 \%$ & $-0.7 \%$ & $3.0 \%$ & Outperformance & $6.9 \%$ \\
\hline Standard deviation & $10.7 \%$ & $7.0 \%$ & $8.0 \%$ & $11.1 \%$ & Tracking error & $12.0 \%$ \\
\hline \multirow[t]{2}{*}{ Sharpe-ratio } & 0.93 & 0.57 & -0.09 & 0.27 & Information ratio & 0.57 \\
\hline & & & & & T-statistic & $2.67^{* * *}$ \\
\hline \multicolumn{7}{|l|}{ 12-1 month momentum } \\
\hline Mean return & $8.1 \%$ & $4.0 \%$ & $3.9 \%$ & $0.2 \%$ & Outperformance & $7.9 \%$ \\
\hline Standard deviation & $11.6 \%$ & $8.1 \%$ & $6.9 \%$ & $10.7 \%$ & Tracking error & $13.0 \%$ \\
\hline \multirow[t]{2}{*}{ Sharpe-ratio } & 0.70 & 0.49 & 0.56 & 0.02 & Information ratio & 0.61 \\
\hline & & & & & T-statistic & $2.82^{* * *}$ \\
\hline \multicolumn{7}{|l|}{ Valuation } \\
\hline Mean return & $8.9 \%$ & $3.3 \%$ & $3.0 \%$ & $1.0 \%$ & Outperformance & $7.9 \%$ \\
\hline Standard deviation & $9.1 \%$ & $7.7 \%$ & $7.9 \%$ & $12.5 \%$ & Tracking error & $13.2 \%$ \\
\hline \multirow[t]{2}{*}{ Sharpe-ratio } & 0.98 & 0.42 & 0.37 & 0.08 & Information ratio & 0.60 \\
\hline & & & & & T-statistic & $2.79^{* * *}$ \\
\hline \multicolumn{7}{|l|}{ Combination strategy } \\
\hline Mean return & $10.4 \%$ & $6.2 \%$ & $1.4 \%$ & $-1.6 \%$ & Outperformance & $11.9 \%$ \\
\hline Standard deviation & $8.7 \%$ & $7.6 \%$ & $9.4 \%$ & $9.9 \%$ & Tracking error & $10.0 \%$ \\
\hline \multirow[t]{2}{*}{ Sharpe-ratio } & 1.19 & 0.81 & 0.14 & -0.16 & Information ratio & 1.19 \\
\hline & & & & & T-statistic & $5.56^{* * *}$ \\
\hline
\end{tabular}


Exhibit 5: Cumulative return Q1-Q4 strategies

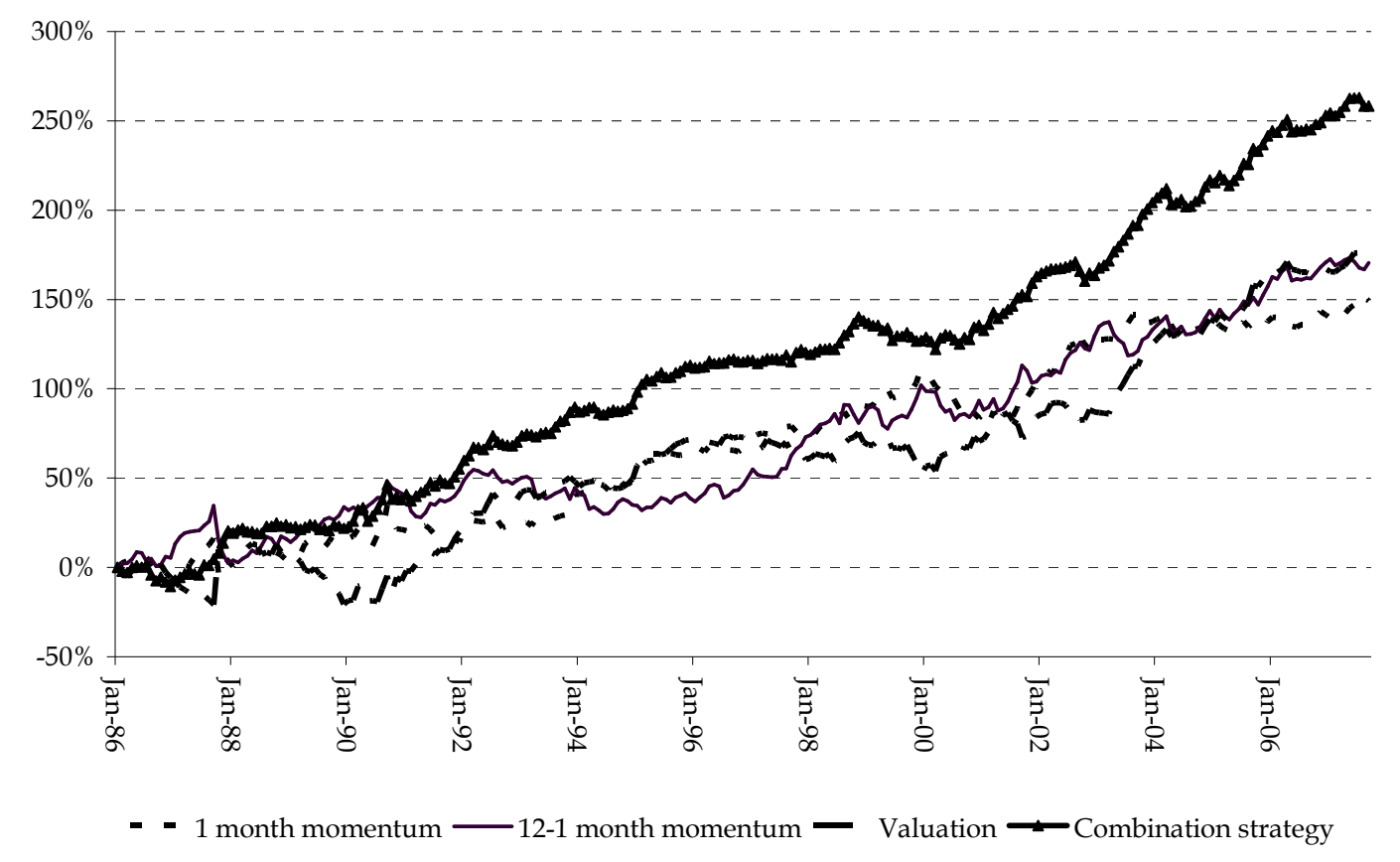


Exhibit 6: Average distribution across quartiles for each asset class

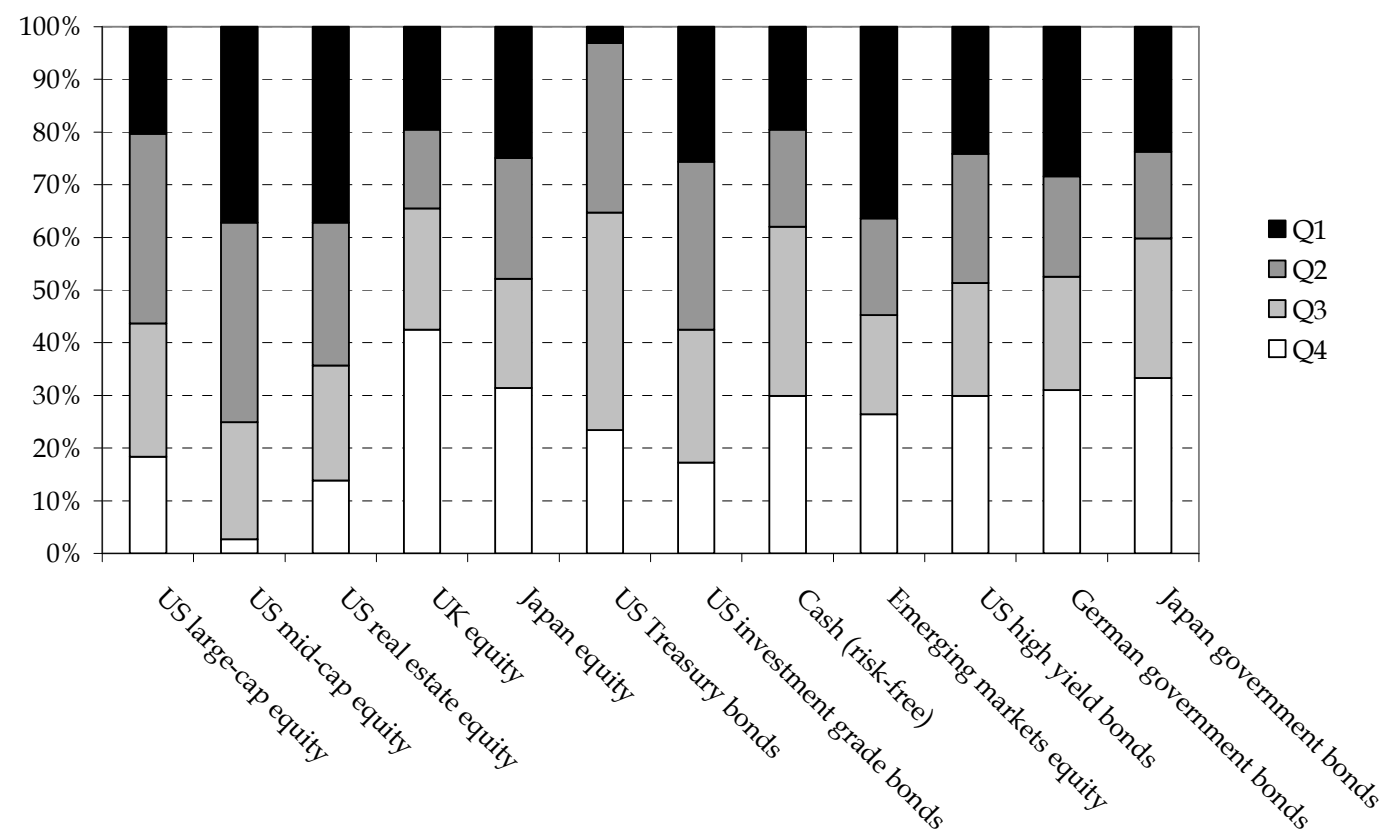


Exhibit 7: CAPM, Fama French 3-factor model and Fama French / Carhart 4-factor model adjusted results for Q1-Q4 strategies, sample period February 1986 through September 2007 (t-statistics in italic)

\begin{tabular}{|c|c|c|c|c|c|}
\hline & Alpha & $\mathbf{R m}$ & SMB & HML & UMD \\
\hline \multicolumn{6}{|l|}{1 month momentum } \\
\hline \multirow[t]{2}{*}{ CAPM } & $6.9 \%$ & 0.00 & & & \\
\hline & $2.64^{* * *}$ & -0.05 & & & \\
\hline \multirow[t]{2}{*}{ Fama French 3-factor model } & $6.8 \%$ & -0.02 & 0.16 & 0.03 & \\
\hline & $2.56^{* *}$ & -0.27 & $2.31^{* *}$ & 0.40 & \\
\hline \multirow[t]{2}{*}{ Fama French / Carhart 4-factor model } & $6.3 \%$ & -0.01 & 0.15 & 0.04 & 0.05 \\
\hline & $2.32^{* *}$ & -0.14 & $2.21^{* *}$ & 0.49 & 0.92 \\
\hline \multicolumn{6}{|l|}{ 12-1 month momentum } \\
\hline \multirow[t]{2}{*}{ CAPM } & $6.9 \%$ & 0.12 & & & \\
\hline & $2.48^{* *}$ & $2.20^{* *}$ & & & \\
\hline \multirow[t]{2}{*}{ Fama French 3-factor model } & $6.5 \%$ & 0.13 & 0.11 & 0.08 & \\
\hline & $2.27^{* *}$ & $2.10^{* *}$ & 1.49 & 0.86 & \\
\hline \multirow{2}{*}{ Fama French / Carhart 4-factor model } & $2.0 \%$ & 0.19 & 0.06 & 0.15 & 0.41 \\
\hline & 0.78 & $3.58^{* * *}$ & 0.89 & $1.83^{*}$ & $8.57^{* * *}$ \\
\hline \multicolumn{6}{|l|}{ Valuation } \\
\hline \multirow[t]{2}{*}{ CAPM } & $9.6 \%$ & -0.21 & & & \\
\hline & $3.42^{* * *}$ & $-3.90^{* * *}$ & & & \\
\hline \multirow[t]{2}{*}{ Fama French 3-factor model } & $8.5 \%$ & -0.17 & 0.14 & 0.18 & \\
\hline & $2.99^{* * *}$ & $-2.77^{* * *}$ & $1.94^{*}$ & $1.99^{* *}$ & \\
\hline \multirow[t]{2}{*}{ Fama French / Carhart 4-factor model } & $11.2 \%$ & -0.21 & 0.17 & 0.14 & -0.25 \\
\hline & $4.03^{* * *}$ & $-3.56^{* * *}$ & $2.46^{* *}$ & 1.59 & $-4.83^{* * *}$ \\
\hline \multicolumn{6}{|l|}{ Combination strategy } \\
\hline \multirow[t]{2}{*}{ CAPM } & $12.4 \%$ & -0.07 & & & \\
\hline & $5.75^{* * *}$ & -1.59 & & & \\
\hline \multirow[t]{2}{*}{ Fama French 3-factor model } & $11.0 \%$ & -0.01 & 0.17 & 0.23 & \\
\hline & $5.11^{* * *}$ & -0.25 & $3.02^{* * *}$ & $3.37^{* * *}$ & \\
\hline \multirow[t]{2}{*}{ Fama French / Carhart 4-factor model } & $11.0 \%$ & -0.01 & 0.17 & 0.23 & 0.00 \\
\hline & $4.98^{* * *}$ & -0.23 & $3.00^{* * *}$ & $3.36^{* * *}$ & 0.07 \\
\hline
\end{tabular}


Exhibit 8: Annualized turnover (one-way) and returns after transaction costs for Q1-Q4 strategies

\begin{tabular}{lccccc}
\hline & \multirow{2}{*}{ Turnover } & \multicolumn{4}{c}{ Performance after transaction costs @ } \\
& & - & $0.10 \%$ & $0.25 \%$ & $0.50 \%$ \\
\hline 1 month momentum & $1675 \%$ & $6.9 \%$ & $3.5 \%$ & $-1.5 \%$ & $-9.9 \%$ \\
$12-1$ month momentum & $491 \%$ & $7.9 \%$ & $6.9 \%$ & $5.4 \%$ & $3.0 \%$ \\
Valuation & $234 \%$ & $7.9 \%$ & $7.5 \%$ & $6.8 \%$ & $5.6 \%$ \\
Combination strategy & $728 \%$ & $11.9 \%$ & $10.5 \%$ & $8.3 \%$ & $4.6 \%$ \\
\hline
\end{tabular}


Exhibit 9: Out of sample test on the period January 1974 to January 1986. Note: 8 assets only

\begin{tabular}{|c|c|c|c|c|c|c|}
\hline & Q1 & Q2 & Q3 & Q4 & & Q1-Q4 \\
\hline \multicolumn{7}{|l|}{1 month momentum } \\
\hline Mean return & $4.7 \%$ & $5.3 \%$ & $-0.6 \%$ & $0.8 \%$ & Outperformance & $3.9 \%$ \\
\hline Standard deviation & $13.7 \%$ & $10.2 \%$ & $11.9 \%$ & $14.6 \%$ & Tracking error & $13.4 \%$ \\
\hline \multirow[t]{2}{*}{ Sharpe-ratio } & 0.35 & 0.51 & -0.05 & 0.06 & Information ratio & 0.29 \\
\hline & & & & & T-statistic & 1.01 \\
\hline \multicolumn{7}{|l|}{ 12-1 month momentum } \\
\hline Mean return & $2.7 \%$ & $4.3 \%$ & $5.2 \%$ & $-2.2 \%$ & Outperformance & $5.0 \%$ \\
\hline Standard deviation & $12.2 \%$ & $11.3 \%$ & $11.2 \%$ & $17.3 \%$ & Tracking error & $18.7 \%$ \\
\hline \multirow[t]{2}{*}{ Sharpe-ratio } & 0.23 & 0.38 & 0.47 & -0.13 & Information ratio & 0.27 \\
\hline & & & & & T-statistic & 0.92 \\
\hline \multicolumn{7}{|l|}{ Valuation } \\
\hline Mean return & $9.1 \%$ & $3.5 \%$ & $-4.8 \%$ & $2.5 \%$ & Outperformance & $6.6 \%$ \\
\hline Standard deviation & $15.3 \%$ & $13.2 \%$ & $9.8 \%$ & $11.9 \%$ & Tracking error & $14.4 \%$ \\
\hline \multirow[t]{2}{*}{ Sharpe-ratio } & 0.60 & 0.26 & -0.49 & 0.21 & Information ratio & 0.46 \\
\hline & & & & & T-statistic & 1.59 \\
\hline \multicolumn{7}{|l|}{ Combination strategy } \\
\hline Mean return & $8.0 \%$ & $4.1 \%$ & $-1.0 \%$ & $-0.7 \%$ & Outperformance & $8.8 \%$ \\
\hline Standard deviation & $13.2 \%$ & $13.2 \%$ & $10.5 \%$ & $12.7 \%$ & Tracking error & $12.7 \%$ \\
\hline \multirow[t]{2}{*}{ Sharpe-ratio } & 0.61 & 0.31 & -0.10 & -0.06 & Information ratio & 0.69 \\
\hline & & & & & T-statistic & $2.39^{* *}$ \\
\hline
\end{tabular}


Exhibit 10: Results using volatility-adjusted returns for each asset class, annualized log excess returns, sample period February 1986 through September 2007

\begin{tabular}{|c|c|c|c|c|c|c|}
\hline & Q1 & Q2 & Q3 & $\mathrm{Q} 4$ & & Q1-Q4 \\
\hline \multicolumn{7}{|l|}{1 month momentum } \\
\hline Mean return & $7.3 \%$ & $6.4 \%$ & $2.1 \%$ & $-0.1 \%$ & Outperformance & $7.4 \%$ \\
\hline Standard deviation & $7.5 \%$ & $7.1 \%$ & $6.1 \%$ & $8.0 \%$ & Tracking error & $9.1 \%$ \\
\hline \multirow[t]{2}{*}{ Sharpe-ratio } & 0.98 & 0.89 & 0.34 & -0.01 & Information ratio & 0.82 \\
\hline & & & & & T-statistic & $3.79^{* * *}$ \\
\hline \multicolumn{7}{|l|}{ 12-1 month momentum } \\
\hline Mean return & $5.6 \%$ & $5.7 \%$ & $3.6 \%$ & $0.7 \%$ & Outperformance & $5.0 \%$ \\
\hline Standard deviation & $8.4 \%$ & $6.1 \%$ & $6.6 \%$ & $7.5 \%$ & Tracking error & $9.6 \%$ \\
\hline \multirow[t]{2}{*}{ Sharpe-ratio } & 0.67 & 0.94 & 0.54 & 0.09 & Information ratio & 0.52 \\
\hline & & & & & T-statistic & $2.40^{* *}$ \\
\hline \multicolumn{7}{|l|}{ Valuation } \\
\hline Mean return & $6.6 \%$ & $4.2 \%$ & $2.5 \%$ & $2.3 \%$ & Outperformance & $4.4 \%$ \\
\hline Standard deviation & $7.3 \%$ & $6.2 \%$ & $7.0 \%$ & $8.3 \%$ & Tracking error & $9.5 \%$ \\
\hline \multirow[t]{2}{*}{ Sharpe-ratio } & 0.92 & 0.68 & 0.36 & 0.27 & Information ratio & 0.46 \\
\hline & & & & & T-statistic & $2.15^{* *}$ \\
\hline \multicolumn{7}{|l|}{ Combination strategy } \\
\hline Mean return & $8.4 \%$ & $4.8 \%$ & $3.2 \%$ & $-0.8 \%$ & Outperformance & $9.2 \%$ \\
\hline Standard deviation & $6.5 \%$ & $7.4 \%$ & $7.3 \%$ & $7.1 \%$ & Tracking error & $7.8 \%$ \\
\hline \multirow[t]{2}{*}{ Sharpe-ratio } & 1.29 & 0.65 & 0.43 & -0.11 & Information ratio & 1.18 \\
\hline & & & & & T-statistic & $5.50^{* * *}$ \\
\hline
\end{tabular}


Exhibit 11: Average monthly excess returns by asset class conditional on quintile classification of combined strategy

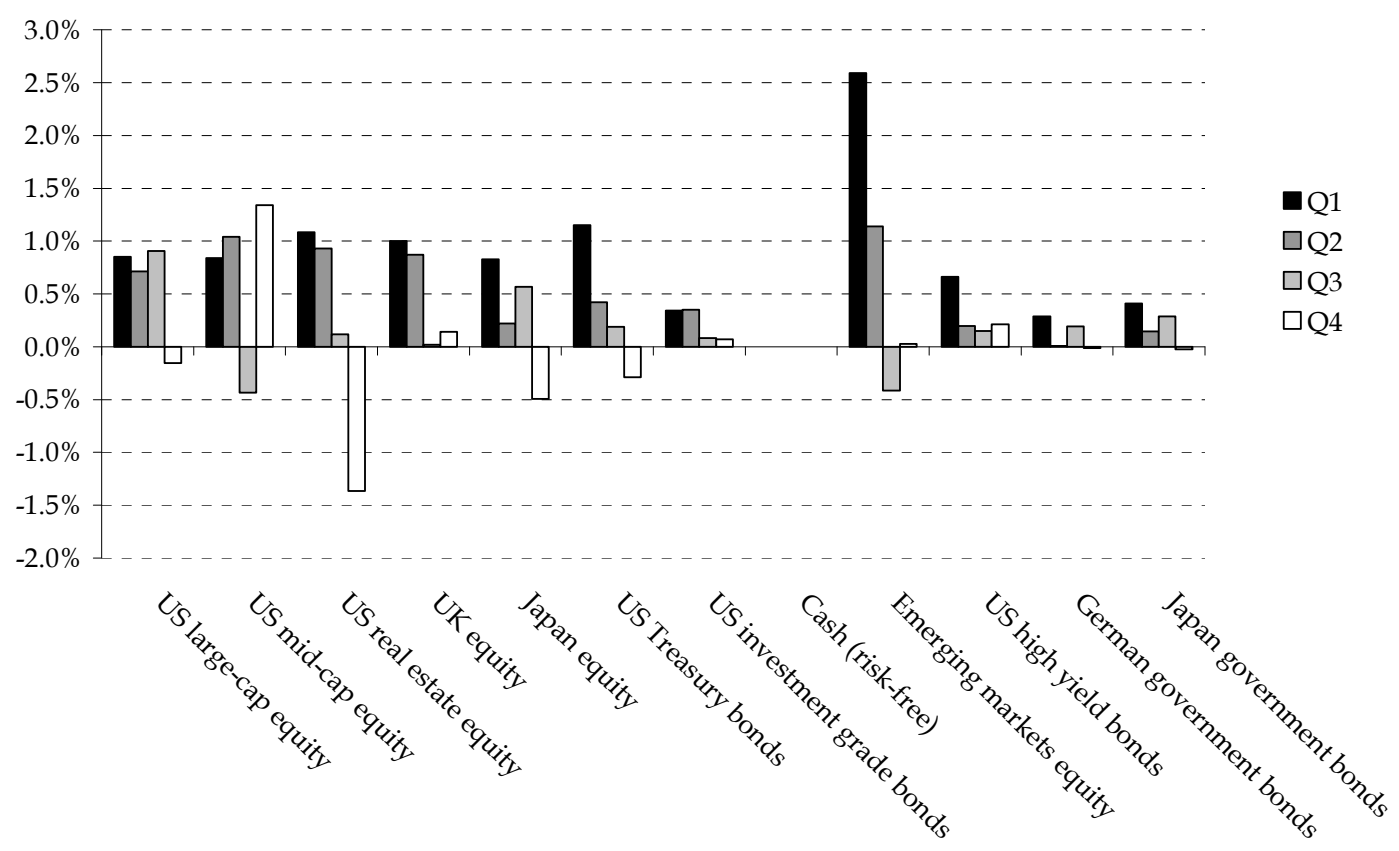


Exhibit 12: GTCAA Q1-Q4 strategy returns in different regimes, sample period February 1986 through September 2007

\begin{tabular}{lcccccccc}
\hline & \multicolumn{2}{c}{ VIX } & \multicolumn{2}{c}{ Term spread } & \multicolumn{2}{c}{ Credit spread } & \multicolumn{2}{c}{ Interest rate } \\
& low & high & low & high & low & high & low & high \\
\hline 1-month momentum & $8.9 \%$ & $6.0 \%$ & $5.2 \%$ & $8.2 \%$ & $6.8 \%$ & $6.8 \%$ & $9.1 \%$ & $4.7 \%$ \\
12-1 month momentum & $9.8 \%$ & $7.1 \%$ & $6.6 \%$ & $8.6 \%$ & $9.6 \%$ & $6.3 \%$ & $7.1 \%$ & $9.4 \%$ \\
Valuation & $9.0 \%$ & $7.2 \%$ & $6.1 \%$ & $9.8 \%$ & $1.1 \%$ & $12.4 \%$ & $14.2 \%$ & $3.5 \%$ \\
Combination strategy & $13.9 \%$ & $10.8 \%$ & $10.7 \%$ & $12.9 \%$ & $9.8 \%$ & $13.4 \%$ & $15.7 \%$ & $8.9 \%$ \\
\hline
\end{tabular}


Exhibit 13: T-statistics of regressions of CSFB/Tremont hedge fund index returns on GTCAA Q1Q4 strategy returns, sample period January 1994 through September 2007. Note: positive relations that are significant at the $5 \%$ level highlighted in bold

\begin{tabular}{lccclc}
\hline Multi-factor regression & $\begin{array}{c}\text { Momentum } \\
\text { MM }\end{array}$ & Momentum & Valuation & Single-factor regression & $\begin{array}{c}\text { Combination } \\
\text { strategy }\end{array}$ \\
\hline Hedge funds & 1.2 & $\mathbf{2 . 7}$ & -2.4 & Hedge funds & -1.5 \\
Convertible arbitrage & -0.6 & 0.2 & 0.0 & Convertible arbitrage & -0.4 \\
Dedicated short bias & -0.4 & -0.6 & 0.0 & Dedicated short bias & -0.7 \\
Distressed & 0.7 & -0.9 & -0.7 & Distressed & 0.4 \\
Emerging markets & 1.8 & -0.6 & -2.9 & Emerging markets & -1.8 \\
Equity market neutral & 0.5 & -0.4 & -1.0 & Equity market neutral & -1.1 \\
Event driven & 0.8 & -0.7 & -0.9 & Event driven & 0.1 \\
Event driven multi-strategy & 0.7 & -0.5 & -1.2 & Event driven multi-strategy & -0.4 \\
Fixed income arbitrage & -0.4 & 1.5 & -0.7 & Fixed income arbitrage & -1.4 \\
Global macro & 1.6 & $\mathbf{2 . 7}$ & -2.3 & Global macro & -1.6 \\
Long/short equity & 0.5 & $\mathbf{3 . 1}$ & -2.0 & Long/short equity & -0.7 \\
Managed futures & $\mathbf{2 . 2}$ & $\mathbf{5 . 4}$ & 1.2 & Managed futures & $\mathbf{2 . 7}$ \\
Multi strategy & -0.1 & $\mathbf{3 . 1}$ & $\mathbf{3 . 1}$ & Multi strategy & $\mathbf{2 . 8}$ \\
Risk arbitrage & 0.2 & -1.7 & 0.6 & Risk arbitrage & 0.9 \\
\hline
\end{tabular}




\section{Publications in the Report Series Research ${ }^{*}$ in Management}

\section{ERIM Research Program: "Finance and Accounting"}

2008

The Inefficient Use of Macroeconomic Information in Analysts' Earnings Forecasts in Emerging Markets Gerben de Zwart and Dick van Dijk ERS-2008-007-F\&A

http://hdl.handle.net/1765/11556

Sole versus Shared Responsibility: Fraud Consultation and Auditor Judgment Anna Gold-Nöteberg, W. Robert Knechel and Philip Wallage ERS-2008-010-F\&A

http://hdl.handle.net/1765/11687

Corporate Governance and the Value of Excess Cash Holdings of Large European Firms Marc B.J. Schauten, Dick van Dijk and Jan-Paul van der Waal

ERS-2008-027-F\&A

http://hdl.handle.net/1765/12465

A Conceptual Model of Investor Behavior Milan Lovric, Uzay Kaymak and Jaap Spronk ERS-2008-030-F\&A

http://hdl.handle.net/1765/12468

Impact of Japanese Mergers on Shareholder Wealth: An Analysis of Bidder and Target Companies Vikas Mehrotra, Dimitri van Schaik, Jaap Spronk and Onno W. Steenbeek ERS-2008-032-F\&A

http://hdl.handle.net/1765/12597

Global Tactical Cross-Asset Allocation: Applying Value and Momentum Across Asset Classes David Blitz and Pim van Vliet

ERS-2008-033-F\&A

http://hdl.handle.net/1765/12598

A complete overview of the ERIM Report Series Research in Management: https://ep.eur.nl/handle/1765/1

ERIM Research Programs:

LIS Business Processes, Logistics and Information Systems

ORG Organizing for Performance

MKT Marketing

F\&A Finance and Accounting

STR Strategy and Entrepreneurship 